SVU- International Journal of Veterinary Sciences, 1 (2): 12-24, 2018.

\title{
Histomorphogenesis of Upper Beak in Muscovy Ducks (Cairina moschata)
}

\section{Kamal E.H. Abdalla1, Salma A. Mohamed², Fatma A. Madkour ${ }^{2 *}$}

${ }^{1}$ Department of Anatomy and Histology, Faculty of Veterinary Medicine, Assuit University 71526, Assuit, Egypt

${ }^{2}$ Department of Anatomy and Embryology, Faculty of Veterinary Medicine, South Valley University 83523, Qena, Egypt

Abstract

The objective of the present work was to provide information on the histology and morphometry of the upper beak of developmental ages of Muscovy Ducks (Cairina moschata) by using fortynine healthy post-hatch Muscovy ducks of both sexes ranging from 1-60 days-old. The upper beak was a wide spoon-shaped in all examined birds. Its length measured $19.32 \mathrm{~mm}$ at one day old and increased to reach $65.52 \mathrm{~mm}$ at 60 days old. The upper beak rostrally formed a smooth circumscribed plate like a finger nail, therefore called the nail of the upper beak, the nail of the upper beak projected rostroventrally beyond the nail of the lower beak. Scanning by electron microscopy revealed that the free tip of the upper beak contained two transversely curved rows of small dome shaped dermal papillae at one-day-old stage. Later, 12-14 transversely curved rows of small papillae were observed behind the dermal papillae at 15 days old, which increased to 18-20 in numbers at 60 days old. In all examined age groups, the lateral edges of the upper beak have lamellae; the ventral parts of the rostrally situated lamellae directed caudally, but the caudally situated lamellae directed vertically. The dermis of the upper beak was formed of dense connective tissue containing numerous lamellated sensory corpuscles on both sides of the lateral edges of the upper beak.

Keywords: Histology, Muscovy Ducks, SEM, Upper beak

Received: August 13, $2018 \quad$ Accepted: September 23, $2018 \quad$ Published: October 1, 2018

*Corresponding Author:Fatma A. Madkour E-mail: madkour.fatma@yahoo.com

Citation: Abdalla et al., Histomorphogenesis of Upper Beak in Muscovy Ducks (Cairina moschata). SVU-IJVS 2018, 1 (2): 12-24.

Copyright: (C) Abdalla et al. This is an open access article distributed under the terms of the creative common attribution license, which permits unrestricted use, distribution and reproduction in any medium provided the original author and source are created.

Competing interest: The authors have declared that no competing interest exists. 


\section{Introduction}

The mallard breed derived all breeds of the domestic duck, which lives in Europe and North America. The Muscovy duck is the only species derived from wild ducks of central and South America (Stastny, 1985). The horny beaks in the birds often have serrations that implement some of the functions of teeth (Kent and Carr, 2001). The bird has a hard beak that can be used for grasping, tearing and scooping the food (Moreng and Avens, 1985). The beaks of birds vary with their diet e.g. seed eaters have a thick beak that acts as a forceps and crushes; raptors have a sharp-edged, hooked beak for tearing meat; and shorebirds have a long, delicate beak for researching food in sandy areas. Beaks enable birds to find, grab, and sometimes kill food items and tear food into smaller pieces to begin the digestive process (Colville and Bassert, 2008). Additionally, the upper bill and tongue of the duck have thermosensitive units, which seem to correspond to cold receptors represented by free ending located in the epidermis (Leitner and Roumy, 1974). In many species of birds, it is also used for defense and protection as well as an adjunct to locomotion by holding and climbing. It is used for routine grooming, preening, mating, communication, feeding young, and habitat exploitation. Beak anatomy is related to its functional importance (Altman, 1997). In duck and goose, spoon-shaped beak is almost completely covered by a soft, yellow waxy skin (Ceroma). The point of the beak is of different texture and forms a hard-horny plate shaped like a finger nail (Nickle et al., 1977). Beak cornification begins in the chicken embryo at 10 days. The bones of the beak are covered by several horny plates. Seasonal proliferation of keratin may be related to normal breeding behaviors and should not be confused with acquired or congenital defects (Clipsham, 1997). The stratum cornium of the external surface of the beak is very hard and this dense cornified layer extends over the tip of the beak to form its hard-cutting edge (Hodge, 1974). By SEM, the dermal papillae at nail of the upper bill have contained the sensory corpuscles of Herbst and Gandry (Berkhoudt, 1976). The available literature revealed that, observations on the anatomy of the upper beak in the birds is inadequate and lacks the necessary details especially that of Muscovy ducks. So, the present study was planned to explain the gross, light and scanning microscopic anatomy on post-hatch development of the upper beak from 1 to 60 days old Muscovy ducks.

\section{Material and methods}

\section{I-Sampling:}

The present study was carried out on a total number of forty-nine healthy post-hatching Muscovy ducks (Cairina moschata) of both sexes ranging from1-60 days old. These ducks were obtained from local farms in Assuit Governorate. They were divided into 5 groups $(1,7,15,30$ and 60 days old). Eleven birds were used for group one day-old; eight birds for group 7 days-old; eleven birds for group 15days-old; eight birds for group 30 days-old; eleven birds used for group 60 days-old. The birds were sacrificed, and all heads were cut off after complete bleeding.

\section{II-Gross morphology and Morphometrical measurements:}

Five birds of each group were used. The heads were washed under running tap water for removal of any traces of blood. For fixation the upper beak was kept in $10 \%$ formalin and various gross anatomy and morphometrical studies were recorded for each bird separately. The different measurements (in millimeters) of different parts of the upper beak were taken out with Precision Digital Vernier Caliper. The length of the upper beak measured from its tip to the 
angle of mouth. All measurements were statistically analyzed by the Statistical Package for Social Science (SPSS) software program, version 17.0.

\section{III-Samples processing for light microscopy:}

Cross, sagittal and longitudinal sections from upper beak were taken from three birds just after sacrificing, washed then fixed in $10 \%$ neutral buffer formalin for one week. After proper fixation, the samples were kept in $10 \%$ solution of Ethylene Diamine Tetra Acetic Acid (EDTA) in phosphate buffered ( $\mathrm{pH}$ 7.4) for the process of decalcification. After good decalcification which determined by touch, the specimens were washed for at least 6 to $12 \mathrm{hrs}$ under running tape water and then dehydrated in ascending grades of alcohol. The samples were cleared in methyl benzoate and embedded in paraffin wax. The time of the paraffin embedding was differed according to the age of the bird which increased by advancement of the age. For example, upper beak of adult ducks was embedded in the paraffin-I for $5 \mathrm{hrs}$, paraffinII for $7 \mathrm{hrs}$, and paraffin-III for $20 \mathrm{hrs,} \mathrm{in}$ $58^{\circ} \mathrm{C}$. Sections of $5 \mu \mathrm{m}$ thickness were taken and stained with Harri's Hematoxylin and Eosin (H\&E) stain was adopted after (Bancroft and Gamble, 2008). The sections were examined with light microscope. The nomenclature used in this study was adopted according to Nomina Anatomica Avium whenever possible (Baumel, et al., 1993).

\section{$I V$-Samples processing for scanning electron microscopy:}

Three birds of only 1, 15 and 60 days-old groups were used. The upper beaks were washed for several times in normal saline and acetic acid $2 \%$, then fixed in $4 \%$ glutaraldehyde solution for 24 hours, then post fixed in $2 \%$ buffered osmium tetraoxide. The fixed samples were washed in $0.1 \mathrm{M}$ cacodylate buffer at PH 7.3, then dehydrated in ascending grades of ethanol, critical pointdried in liquid carbon dioxide, and mounted on metal stubs then coated with gold palladium in sputtering device. Specimens were then examined and photographed using JSM-4500 LV scanning electron microscope operated at $20 \mathrm{KV}$.

\section{Result}

\section{I- Gross anatomy \& morphometrical studies:}

The upper beak of Muscovy duck was a wide spoon-shaped; it consisted of a bony support covered by a horny keratin (Fig. 1A). The beak was soft and could be compressible in the young ages (1-15days old) and later became harder up to 30 days old. The maximum hardness was noticed on the nail of the beak.

The statistical data clarified that the total length of the upper beak was $(19.32 \pm 0.59 \mathrm{~mm})$ at one day-old. It increased gradually to form nearly one and half folds $(31.53 \pm 0.66 \mathrm{~mm})$ at 15 days old and three and half folds $(65.52 \pm 4.0 \mathrm{~mm})$ at 60 days old when compared with that at one day old. The upper beak in all studied ages increased in height caudally. At one day old the height was $3.13 \pm 0.22,7.03 \pm 0.20$ and $7.19 \pm 0.16 \mathrm{~mm}$ at the level of the nail, nostril and angle of the mouth. With further development, it increased to become at 60 days old $7.72 \pm 0.56,21.97 \pm 1.46$ and $24.28 \pm 2.41 \mathrm{~mm}$ respectively. It was cleared that, the height of the beak at 60 days old was about two and half, three, three and half folds when compared it with that at one day old at the level of the three before mentioned structures respectively.

The upper beak had three surfaces (two dorso-lateral and one ventral) and two lateral edges. Both the dorsolateral surfaces were flat and separated at the midline of the dorsum by a prominent ridge which lied between the levels of the nostrils and extends rostrally to reach the nail. The caudal two thirds of the dorsolateral surface were demarcated ventrally from the lateral edge of 
the upper beak by faint groove which began at the angle of the mouth and extends rostrally for $11.05 \pm 0.45 \mathrm{~mm}$ at one day. With the advancement of the age, this groove became distinct and increased in length to reach $21.51 \pm 0.72 \mathrm{~mm}$ at 15 days old and $42.73 \pm 4.40 \mathrm{~mm}$ at 60 days old. Another faint groove could be observed on the rostral third of the dorsolateral surface at 1-7 days old. This groove located dorsal to the anteriorly directed groove; it began before the termination of the latter groove and extends rostrally for $4.21 \pm 0.17 \mathrm{~mm}$ at one day and $6.05 \pm 0.23$ at 7 days old to reach the nail. In the later development, the dorsal groove became distinct and increased in length to reach $9.66 \pm 0.75, \quad 15.72 \pm 0.47$ and $17.26 \pm 2.37 \mathrm{~mm}$ at 15,30 and 60 days old respectively (Fig. 1B). The morphometrical studies indicated that in all examined ages, the length of the ventral groove formed about $2.17-2.62 \%$ of that of the dorsal groove. Moreover, the distance between the rostral end of the ventral groove and the caudal end of the dorsal groove measured $1.39 \pm 0.03 \mathrm{~mm}, 1.39 \pm 0.14 \mathrm{~mm}$ at 1,7 days old respectively. It increased in the older duck to reach $3.35 \pm 0.51 \mathrm{~mm}$ at 60 days old. Therefore, this distance at 60 days old was nearly two and half folds at 7 days old.

Rostrally, the upper beak formed a smooth circumscribed plate like a finger nail, therefore called the nail of the upper beak (Fig.1A). It was limited to a small median part of the tip and was harder in texture than the surrounding horny beak. The rostral free edge of this nail of the upper beak was thin and projected rostroventrally beyond the nail of the lower beak. Dorsally, the nail of the upper beak was smooth and convex from side to side. While ventrally, its caudal part was covered by the mucosa of the palate, therefore the rest part of the nail had a crescentic appearance (Fig.1C). The length (rostro-caudal diameter) of the upper nail was $7.13 \pm 0.18 \mathrm{~mm}$ while its width (at widest part) $6.91 \pm 0.15 \mathrm{~mm}$ at one day old. At 7 days old the two dimensions are $7.73 \pm 0.30 \mathrm{~mm}$ and $7.74 \pm 0.31 \mathrm{~mm}$, respectively. It clearly showed that both dimensions were nearly equal at 1-7 days old. With the advancement of the age, the length of the upper nail increased at a rapid rate than the width and they became $9.65 \pm 0.23 \mathrm{~mm}, 7.44 \pm 0.22 \mathrm{~mm}$ at 15 days old, $14.56 \pm 0.58 \mathrm{~mm}$, $11.60 \pm 0.47 \mathrm{~mm}$ at 30 days old and $17.78 \pm 1.08 \mathrm{~mm}, 13.21 \pm 0.84 \mathrm{~mm}$ at 60 days old, respectively. The length (rostro-caudal diameter) of the ventral aspect of the upper nail was $1.35 \pm 0.05,1.38 \pm 0.12,2.24 \pm 0.05$, $2.65 \pm 0.05$ and $3.88 \pm 0.51 \mathrm{~mm}$ at $1,7,15,30$ and 60 days, respectively.

The ventral surface of the upper beak was deeply concave and forming the roof of the oral cavity. The lateral edge (tomium) of the upper beak was smooth laterally but lamellated medially along its entire length except at the nail region (Fig.1C). At day old stage, a thin row of lamellae was identified on the medial aspect of the lateral edge of the upper beak. At 7-15 days old, the medial aspect was occupied by numerous small sized lamellae, which had both dorsal and ventral ends. At 30-60 days old stage, the lamellae became thicker and longer. In addition, at this period of development, the ventral ends of the rostrally situated lamellae were directed caudally, while those of caudally situated lamellae were directed transversally.

Concerning to the length of the lamellae, it was noticed that the lamellae at the mid region of the lateral edge of the upper beak were longer than those at both ends. The interlamellar spaces were relatively wider rostrally than caudally.

At 30-60 days, the attached dorsal ends of the lamellae were broader than the ventral free ends. Moreover, the dorsal part of the lamellae was grooved; therefore, their dorsal attached ends appeared to be bifurcated. 
Another small additional groove could be distinguished on some lamellae. When the beak was closed, the lamellae of its lateral edge interdigitated with the lingual marginal papillae.

At the base of the upper beak and on both sides of its dorsolateral surfaces, it presented the nostrils, which were oval in shape at 115 days old and became elliptical at 30-60 days (Fig.1B). At one day-old, the nostrils were located $11.52 \mathrm{~mm}$ caudal to the tip of the upper beak and $4.34 \mathrm{~mm}$ above the level of its lateral edge. The distance between nostrils and previously mentioned landmarks got increased with the advancement of the age to reach $37.40 \mathrm{~mm}$ and $14.26 \mathrm{~mm}$, respectively at 60 days old. The length (rostro-caudal diameter) of the nostril at one day was $1.74 \mathrm{~mm}$, which later increased to become $3.78 \mathrm{~mm}$ at 15 days and $9.13 \mathrm{~mm}$ at 60 days-old.

The width (dorsoventral diameter) of the nostrils at one day was $1.10 \mathrm{~mm}$, which later increased to become $1.86 \mathrm{~mm}$ at 15 days and reached $3.96 \mathrm{~mm}$ at 60 days. Concerning to the relationship of the distance between the tip of the upper beak and the eye in one side and tip of the upper beak and the nostril on the other side, it was noticed that the nostril in all studied developmental ages located nearly in the midway between the tip of the beak and eye. All the measurements of the upper beak are statistically depicted in Table (1).
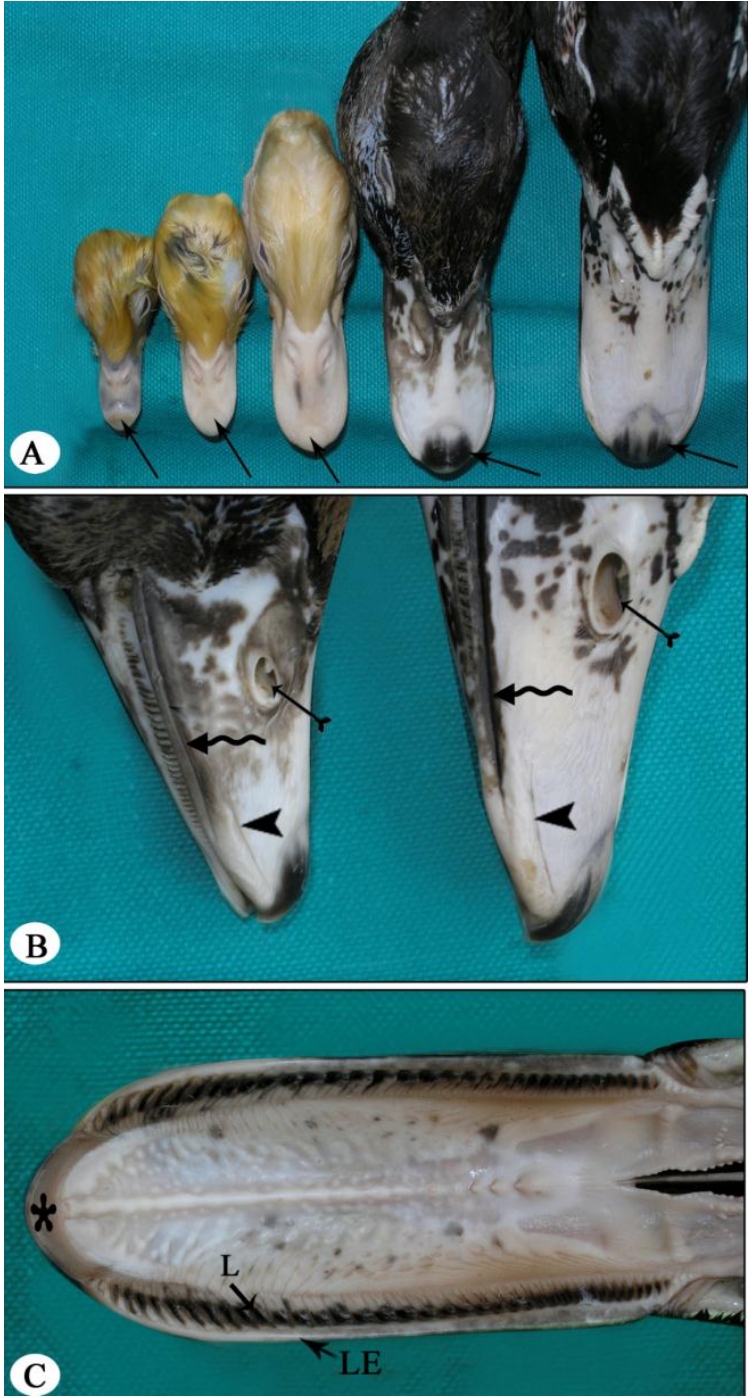

Fig. 1. Photographs of the upper beak. (A) the dorsal aspect of the upper beak at 1, 7, 15, 30 and 60 days-old from left to right showing the upper nail (arrow), (B) the lateral aspect of the upper beak at 30 and 60 days-old showing ventral groove (twisted arrow), dorsal groove (arrow head), nostrils (barbed arrow), and (C) the ventral aspect of the upper beak at 60 days-old showing lateral edge of upper beak (LE), medial row lamellae (L) and ventral surface of the upper nail (star). 
Table 1. Measurements of the upper beak (mm). This table is showing the length and height of the upper beak, distances between the tip of the upper beak and nostril or eye, distances between nostril and eye or lateral edge of the upper beak, length of ventral and dorsal groove and distance between them, nail length and width, and nostril length and width.

\begin{tabular}{|c|c|c|c|c|c|c|}
\hline \multicolumn{2}{|c|}{ Parameter (mm) / Age (days) } & 1 day & 7 days & 15 days & 30 days & 60 days \\
\hline \multicolumn{2}{|c|}{ Upper beak (UB): a. Length } & $19.32 \pm 0.59$ & $23.80 \pm 0.46$ & $31.53 \pm 0.66$ & $52.82 \pm 1.53$ & $65.52 \pm 4.00$ \\
\hline $\begin{array}{l}\text { Distance } \\
\text { between: }\end{array}$ & $\begin{array}{l}\text { a. Tip of UB and nostril } \\
\text { b. Tip of UB and eye } \\
\text { c. Eye and nostril } \\
\text { d. Nostril \& UB lateraledge }\end{array}$ & $\begin{array}{l}11.52 \pm 0.43 \\
24.81 \pm 0.86 \\
11.67 \pm 0.30 \\
4.34 \pm 0.17 \\
\end{array}$ & $\begin{array}{l}13.98 \pm 0.45 \\
30.05 \pm 0.73 \\
13.17 \pm 0.43 \\
4.86 \pm 0.32 \\
\end{array}$ & \begin{tabular}{|l|}
$19.61 \pm 0.60$ \\
$41.85 \pm 0.84$ \\
$19.23 \pm 0.43$ \\
$7.66 \pm 0.14$ \\
\end{tabular} & $\begin{array}{l}31.63 \pm 0.82 \\
65.94 \pm 2.00 \\
29.35 \pm 0.97 \\
11.49 \pm 0.53 \\
\end{array}$ & $\begin{array}{l}37.40 \pm 3.69 \\
82.66 \pm 6.66 \\
34.60 \pm 2.92 \\
14.26 \pm 0.23 \\
\end{array}$ \\
\hline $\begin{array}{l}\text { Height } \\
\text { of UB at: }\end{array}$ & $\begin{array}{l}\text { a. Nail } \\
\text { b. Nostril } \\
\text { c. Angle of mouth }\end{array}$ & $\begin{array}{l}3.13 \pm 0.22 \\
7.03 \pm 0.20 \\
7.19 \pm 0.16\end{array}$ & $\begin{array}{l}3.44 \pm 0.31 \\
9.06 \pm 0.68 \\
8.39 \pm 0.27\end{array}$ & $\begin{array}{l}4.94 \pm 0.25 \\
13.25 \pm 1.67 \\
12.04 \pm 0.45\end{array}$ & $\begin{array}{l}7.14 \pm 0.30 \\
17.51 \pm 0.90 \\
19.00 \pm 0.62\end{array}$ & $\begin{array}{l}7.72 \pm 0.56 \\
21.97 \pm 1.46 \\
24.28 \pm 2.41\end{array}$ \\
\hline Grooves: & $\begin{array}{l}\text { a. Ventral groove length } \\
\text { b. Dorsal groove length } \\
\text { c. Distance between } \\
\text { ventral \& dorsal groove } \\
\end{array}$ & $\begin{array}{l}11.05 \pm 0.45 \\
4.21 \pm 0.17 \\
1.39 \pm 0.03\end{array}$ & $\begin{array}{l}13.49 \pm 0.47 \\
6.05 \pm 0.23 \\
1.39 \pm 0.14\end{array}$ & $\begin{array}{l}21.51 \pm 0.72 \\
9.66 \pm 0.75 \\
2.31 \pm 0.15\end{array}$ & $\begin{array}{l}34.25 \pm 1.54 \\
15.72 \pm 0.47 \\
3.03 \pm 0.15\end{array}$ & $\begin{array}{l}42.73 \pm 4.40 \\
17.26 \pm 2.37 \\
3.35 \pm 0.51\end{array}$ \\
\hline Nail: & $\begin{array}{l}\text { a. Dorsal surface length } \\
\text { b. Dorsal surface width } \\
\text { c. Ventral surface length }\end{array}$ & $\begin{array}{l}7.13 \pm 0.18 \\
6.91 \pm 0.15 \\
1.35 \pm 0.05\end{array}$ & $\begin{array}{l}7.73 \pm 0.30 \\
7.74 \pm 0.31 \\
1.38 \pm 0.12\end{array}$ & $\begin{array}{l}9.65 \pm 0.23 \\
7.44 \pm 0.22 \\
2.24 \pm 0.05\end{array}$ & $\begin{array}{l}14.56 \pm 0.58 \\
11.60 \pm 0.47 \\
2.65 \pm 0.05\end{array}$ & $\begin{array}{l}17.78 \pm 1.08 \\
13.21 \pm 0.84 \\
3.88 \pm 0.51\end{array}$ \\
\hline Nostrils: & $\begin{array}{l}\text { a. Length } \\
\text { b. Width }\end{array}$ & $\begin{array}{l}1.74 \pm 0.06 \\
1.10 \pm 0.00\end{array}$ & $\begin{array}{l}1.70 \pm 0.21 \\
1.49 \pm 0.15\end{array}$ & $\begin{array}{l}3.78 \pm 0.16 \\
1.86 \pm 0.03\end{array}$ & $\begin{array}{l}6.33 \pm 0.12 \\
2.57 \pm 0.06\end{array}$ & $\begin{array}{l}9.13 \pm 0.87 \\
3.96 \pm 0.37 \\
\end{array}$ \\
\hline
\end{tabular}

\section{II- Light microscopy:}

In cross sections, the upper beak of the one-day old ducks was consisted of a bony base-covered by skin, which was thicker on the lateral edges than the other parts of the upper beak (Fig.2A). The skin was composed of two layers viz. epidermis and dermis. The epidermis was composed of 3 main layers i.e. stratum basale, stratum spinosum and stratum cornium. The dermis was formed of dense connective tissue containing blood vessels and small lamellated sensory corpuscles. The sensory corpuscles were most frequently located on both sides of the lateral edges of the upper beak beneath the stratum basale.

The bony base was consisted of premaxilla bones of spongy type, formed by irregular bony trabeculae which were separated by narrow marrow spaces containing haemopoietic cells. In general, the spongy bone was relatively thicker in the middle and became thinner laterally. The spongy bone appeared as two plates in the midway of each side of the upper beak (Fig.2A).

A narrow ventral groove was found as right and left depressions on the lateral edges of the upper beak. The depth of this groove was continuous with the surface keratinized skin of the upper beak. Moreover, the developing medial row lamellae were represented by short pointed keratinized projections on the medial aspect of the lateral edges of the upper beak (Fig.2A). Each lamella was formed by a thin connective tissue core covered by keratinized epithelium with no bony basis. The lamellae of the lateral edge were situated opposite to the ventral groove (Fig.2B). In longitudinal sections (Fig.2C), the free tip of the upper beak "upper nail" was more keratinized than the other parts of the upper beak. The covering keratin layer of 
the upper nail continued caudally with the keratinized layer of the stratified epithelium of the upper beak on the ventral aspect. The sensory corpuscles were demonstrated within the dermal connective tissue of the upper beak.

In cross sections, the covering skin of the upper beak of 7-15 days old ducks had a thicker keratinized epidermis and denser connective tissue dermis in comparison to that at one day old ducks. The supporting spongy bone appeared as thicker trabeculae forming the dorsal and ventral bony lamellae (Fig.2D). The ventral groove became deeper than that of the one-day old ducks, and the horny lamella which situated opposite to it was enlarged (Fig.2E). At 30-60 days (Fig.2F), dorsally covering skin was found to be thicker and the dermis consist the dense irregular connective tissue which was rich in collagen fibers and larger sensory corpuscles. The keratin covering of the medial row lamellae of the lateral edges of upper beak appeared thicker than that in the previous ages. The supporting bony basis was still of spongy type, but some compact bone lamellae were also observed. This compact bone was expected to form the future bone (Fig. 2F, G). The dorsal and ventral grooves were represented by two depressions on the dorsolateral surface of the upper beak.

\section{III- Scanning electron microscopy}

The scanning electron microscopic observations showed two transversely curved rows of small ventrally directed dome shape dermal papillae on the free tip of the upper beak at one day (Figs.3A, B). These papillae had blunt free ends and were encircled by circular groove, which was surrounded by 2-3 small layers of keratin. At 15 days, the dermal papillae were increased in size and the grooves encircling their bases were surrounded by 3-4 layers of keratin. At higher magnification, the sur-

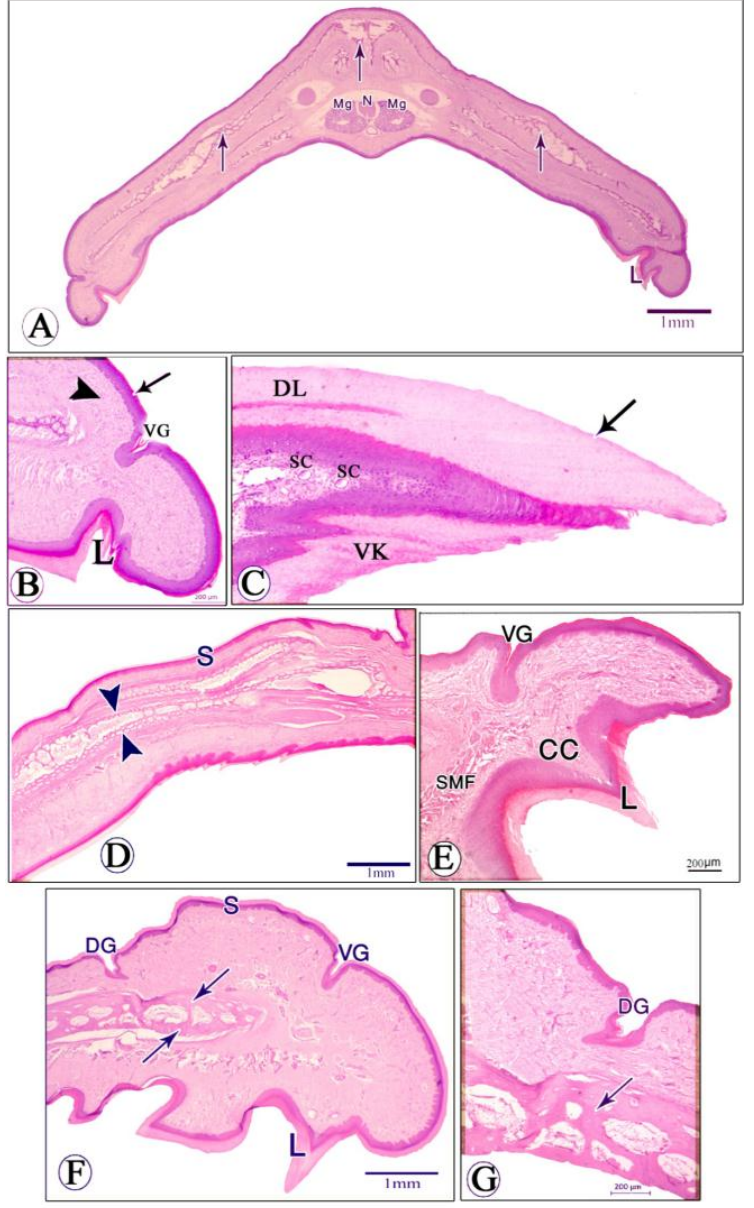

Fig. 2. Photomicrographs of cross section of the upper beak stained with H\&E stain. At one day (A-C*) showing 2 maxillary glands $(\mathrm{Mg}), 2$ nerve trunks $(\mathrm{N})$, spongy bone (arrows) and medial lamella (L) in (2.A), and showing keratinized epidermis (arrow), dermis (arrow head) and ventral groove (VG) opposite to medial lamella (L), upper nail (arrow), dorsal keratin (DK), ventral keratin (VK) and sensory corpuscles (SC) in (2.B and C). At 15 days (D, E) showing skin of upper beak (S) and dorsal and ventral spongy lamellae (arrow heads), ventral groove (VG) opposite to medial lamella (L) contained connective tissue core (CC) and smooth muscle fibers (SMF). And at 60 days-old $(F, G)$ showing skin of upper beak (S), ventral groove (VG), dorsal groove (DG), compact bone (arrows) and medial lamella (L). * Photomicrograph $\mathrm{C}$ is a longitudinal section of the upper beak of one day old stained with H\&E stain. 
-faces of the dermal papillae appeared to be surrounded by few layers of keratin. In addition, at this age 12-14 transversely curved rows of papillae were observed behind the dermal papillae. These papillae appeared as cylindrical in shape and surrounded by few layers of keratin (Figs. 3C, D). At 60 days, the dermal papillae became distinct and their surface epithelium was surrounded by layers of keratin. The grooves encircled their bases and were surrounded by 5-6 layers of keratin. Moreover, the transversely curved rows of papillae were located behind the dermal ones and became 18-20 in number. They increased in size and surrounded by several layers of keratin giving them scroll like appearance (Figs.3E, F).
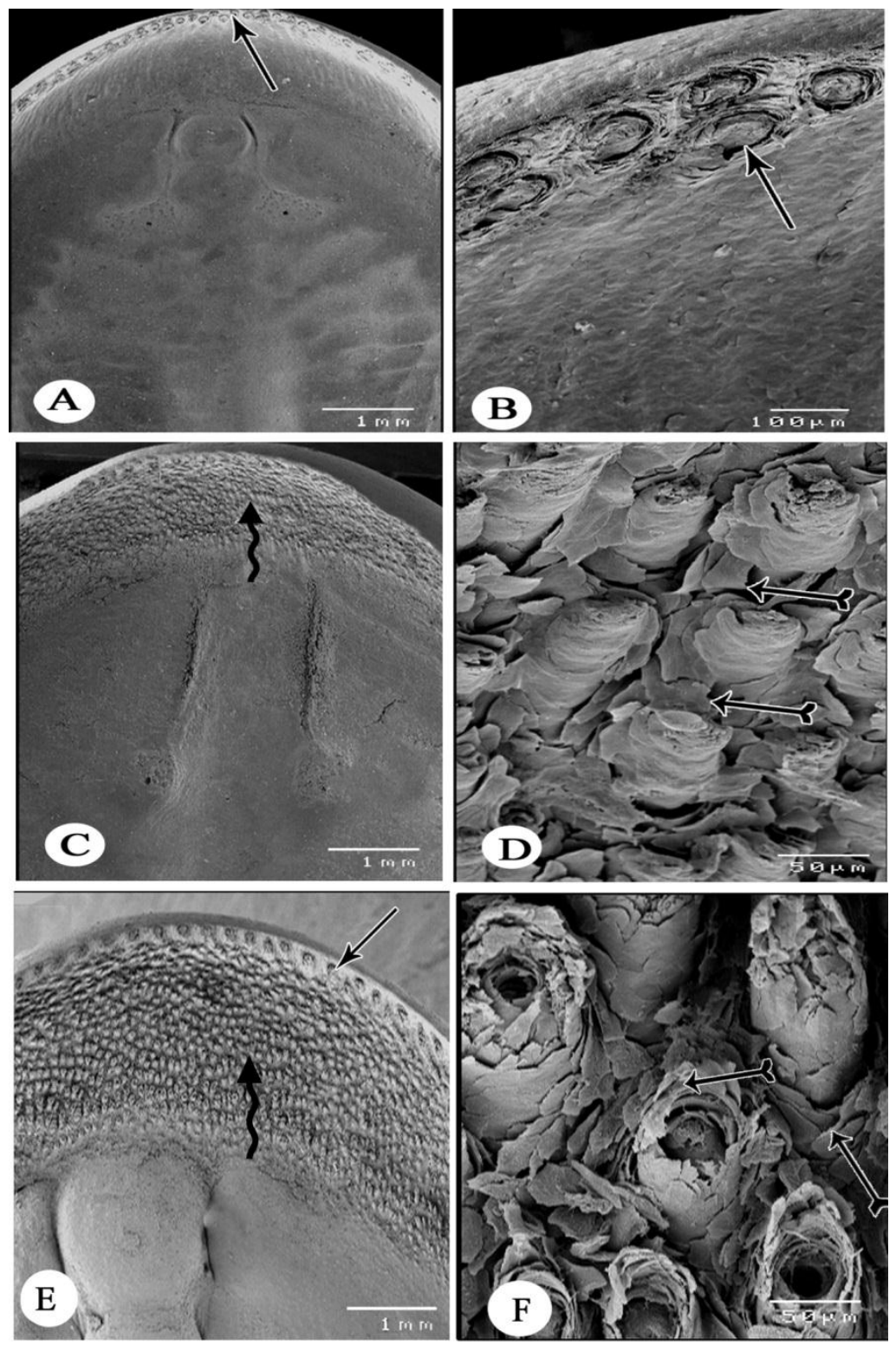

Fig. 3. Scanning electron micrographs of the tip of the upper beak. Scanning electron micrographs at one day (A, B), 15 days (C, D), and 60 days old (E, F) showing rows of dermal papillae (arrow), several rows of small papillae (twisted arrow), and few to several layers of keratin surround cylindrical papillae (barbed arrows). 
The shape of the medial row lamellae of the lateral edge of the upper beak varied with the age of the birds. At one day, the lamellae along the length of the beak were generally straight. With the advancement of the age, the rostrally placed lamellae became curved at 15 days old. This curvature became pronounced at 60 days old. However, the caudally placed lamellae were straight in both ages. Regarding, the direction of the lamellae, it was noticed that in all examined ages the ventral parts of the rostrally placed lamellae were directed caudally, but the caudally placed lamellae were vertically directed (Figs. 4, 5).

Concerning to the rostrally situated lamellae, few fine grooves were observed on their dorsal parts in one day old ducks. These grooves were distinct at higher magnification (Fig. 4A, B). At 15 days, the grooves became deep; therefore, the lamellae appeared bifurcated dorsally into two branches (Figs. 4C). In addition, a fine groove (regrooving) could be observed at one of these dorsal branches (Fig. 4D). At 60 days, the dorsal halves of the lamellae were appeared as bifurcated. Moreover, each branch was regrooved. Consequently, the dorsal parts of the lamellae appeared to be divided into four branches and the ventral parts of the lamellae were concave caudally and convex rostrally (Fig. 4E, F). However, the caudally situated lamellae were characterized in all examined ages by presence of the median groove at their dorsal halves (Fig.5 A-C).
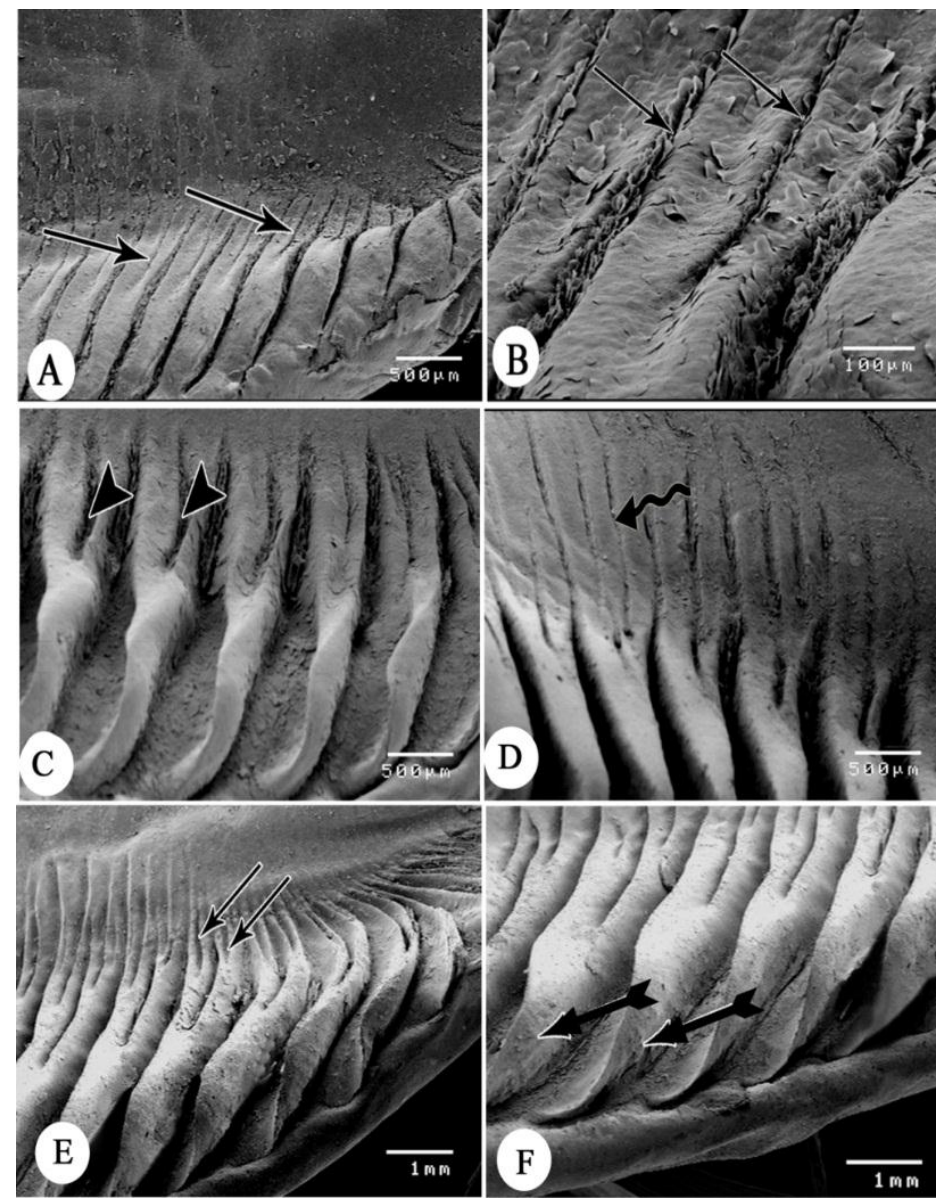

Fig. 4. Scanning electron micrographs of the lateral edge of upper beak. Scanning electron micrographs of the lateral edge of upper beak at one day (A, B), 15 days (C, D), and 60 days old (E, F) showing fine grooves on the dorsal parts of the most rostral lamellae (arrows), bifurcated dorsal parts of the lamellae into two branches (arrow heads) and the ventral parts of the lamellae are curved caudally, fine groove (regrooving) at one branch of the dorsal part of the lamellae (twisted arrow), regrooving of the bifurcated dorsal parts of the lamellae (double arrows), the ventral parts of the lamellae are concave caudally and convex rostrally (barbed arrows). 

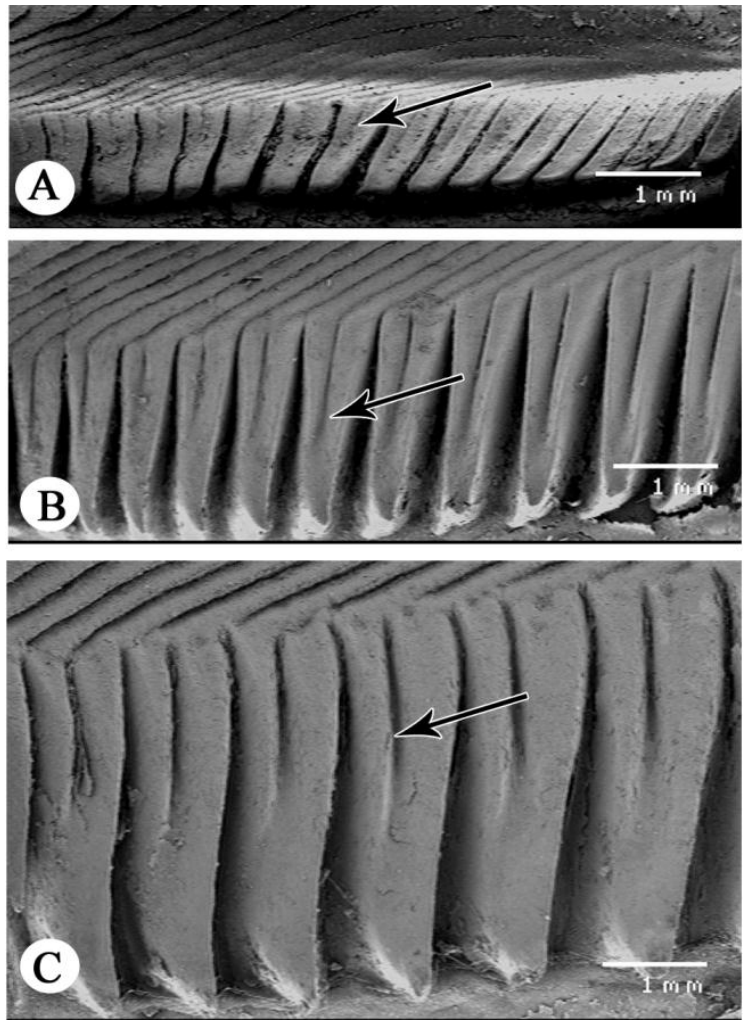

Fig. 5. Scanning electron micrographs of the lateral edge the upper beak. Scanning electron micrographs of the lateral edge the upper beaks at one day (A), 15 days (B), and 60 days-old (C) showing nearly straight caudally situated lamellae with the median grooves at their dorsal parts (arrow).

\section{Discussion}

The present study revealed that the beak was soft and compressible in the young ages (1-15days old ducks) which became harder at 30 days. Similarly, in the duck and goose, both beaks carry a horny sheath which is relatively soft and flexible (Nickle et al., 1977). Most of the upper bill is usually covered by hard keratin. Whereas, it was found in contrast with the reports in waders (shore-birds), i.e. Charadrii, however, the whole bill is relatively soft, whilst in the Anatidae, only the tip or dertrum of bill is hardened as the nail or neb (McLelland, 1979) and in ostrich, both beaks are covered by a hard-horny sheath which is relatively flexible (Tadjalli et al., 2008).
The statistical data showed that the length of the upper beak was $19.32 \pm 0.59 \mathrm{~mm}$ at one day. It later increased to become 1.5 folds and 3.5 folds at 15 and 60 days, respectively when compared with that at one day whereas in ostrich, the mean length of upper beak was $6.3 \mathrm{~cm}$ (Tadjalli et al., 2008). Previously published reports suggest that the size and shape of the beak are related not only to the type of food the birds eat but also to their means of food prehension and the size of beak seems to be an important factor in the regulation of ingestion (Nickle et al., 1977and Tadjalli et al., 2008). In agreement with McLelland (1975) in duck that the nail was limited to a small median part of the tip of upper beak but disagreed with that reported in goose whereas this nail completely covers the tip. In Anseriformes, "the nail", a shield like formation at the tip of the upper bill, is used for grazing or catching mollusks. While, the most rostral extremity of both upper and lower bills of emu display a distinct hook-like or nail-like structure, the mandibular and maxillary nail (Crole and Soley, 2010), and a structure is also evident in the ostrich (Tivane, 2008) but not in the kiwi (Roach, 1952). The present morphometrical study explained that at 1-7 days, the length and width of the upper nail were nearly equal. With the advancement of age, the length of the upper nail increased at a rapid rate than its width. In straining species e.g., the Mallard (Anas platyhynchos) and the Ruddy Duck (Oxyura jamaicensis) the apex of the bill is broad, and the nail is narrow, because a grasping action not being required (McLelland, 1979). The upper and lower nails, and serrations on the rostral lower tomia, provide the emu with a great combination of gripping, tearing and pecking power (Crole and Soley, 2010).

The present work showed grossly that the lateral edge of the upper beak was smooth laterally but lamellated medially along its length except at the nail region. 
This agreed with the findings of McLelland (1979), that in the majority of the duck, goose and swans (Anatidae) one row of lamellae is present on the upper beak. In contrast, the lamellae in straining species e.g. the Mallard and the Ruddy duck are blade like act with the bristles and processes of the tongue to filter out solid food particles from water. Nudds and Bowlby (1984) suggested that interspecific variation in the interlamellar spacing alone leads to partitioning of prey by size. On contrast in emu, the maxillary tomia were smooth (nonserrated) and narrower than mandibular tomia (Crole and Soley, 2010).

The present investigation revealed that the nostrils located at the base of the upper beak which were oval in shape at 1-15 days old and became elliptical at 30-60 days old. The nostril opening length was $1.74 \mathrm{~mm}$, $3.78 \mathrm{~mm}$, and $9.14 \mathrm{~mm}$ at 1,15 and 60 days respectively. In this concern, King (1975) reported in the duck that the opening of the nostril is about 5 to $7 \mathrm{~mm}$ long. In the fowl, the nostril is an elongated narrow slit is about 7 to $9 \mathrm{~mm}$ long. The latter authors added that the operculum is absent in the aquatic species. Perrins (1982) recorded that in kiwi; nostrils are placed near to the bill tip and probably enable the bird to smell food underground when it is probing for food.

The current work showed that the skin of the upper beak was thicker on the lateral edges than the other parts of the upper beak. While Hodges (1974) mentioned that in fowl, in the anterior region of the buccal cavity, inside the beak itself, the dermal layer is thin and cannot be subdivided into tunica propria and submucosa. Clipsham (1997) reported in chicken that, the dermis is an extremely thin, highly vascular layer sandwiched between two hard substances. The dermis of the studied beak was formed of dense connective tissue containing blood vessels and small lamellated sensory corpuscles. These corpuscles were most frequently located on both sides of the lateral edges of the upper beak. In this connection, herbst's corpuscles occur frequently in the skin, upper beak of chickens and in the tongue of some birds (King, 1975, Banks, 1993, Farner et al., 2012). The sensory corpuscles acted as vibration and pressure receptors in the tongue and beak of birds (Banks, 1993). Perrins (1982) stated that, herbst corpuscles enable the birds to feel prey which they cannot see.

When viewed with scanning electron microscopy, the free tip of the upper beak contained two rows of dome shaped dermal papillae at one day. These dermal papillae followed by 12-14 transversely curved rows of small papillae at 15 days, 18-20 in numbers at 60 days. In this respect, Berkhoudt (1975) mentioned in duck that the upper nail has a series of ventrally directed pores through which protrude dermal papillae. In goose, it has been suggested that the presence of those dermal papillae may enable a higher resolution of tactile sensory information (Gottschaldt and Lausmann, 1974). In the Mallard (Zweers and Wouterlood, 1973), and in many other species, determination of food occurs at the level of the beak tip organ. The bills are importance for feeding on particular food items (Zusi, 1987, Benkman and Lindholm, 1991).

The present studies showed that the bases of the dermal papillae which situated at the tip of the upper beak encircling by grooves and the surface of the papillae locating behind the dermal papillae were surrounded by layers of keratin which increased in their number and size with the advancement of the age. In this connection, the dermal papillae of the duck are covered distally by caps of keratin (Berkhoudt, 1975). The keratin is continually lost by wear and replaced by new growth. The location and rate of growth and wear influence the exact shape of the beak and subtle changes may occur as food type's change (Klasing, 1999). Gentle and Breward,1986) suggested that the reduced 
keratinization of the cells in the tip of the papillae permits a greater displacement of the softer tissue than the surrounding rhamphotheca and allowed for an increased sensitivity.

\section{Conclusion}

In all examined ages, the upper beak of Muscovy ducks was wide spoon-shaped. The median part of upper beak had a smooth circumscribed plate (nail of the upper beak). The bony basis of beak consisted of premaxillary bones of spongy type but by older ages some compact bone lamellae were also observed. Medial row of lamellae was observed on the lateral edge of the upper beak which was interdigitated with the lingual marginal papillae during closed mouth to filter foods from water.

\section{Acknowledgement}

The authors express their deepest gratitude to the members of Histology Department, Faculty of Veterinary Medicine, South Valley University, Egypt for their helpful comments and valuable suggestions.

\section{References}

Altman R B (1997). Beak Repair; Acrylics: In Avian Medicine and Surgery. Saunders Company, Philadelphia, London and Toronto.

Bancroft J D and Gamble M (2008). Theory and practice of histological techniques, Elsevier Health Sciences.

Banks W J (1993). Applied veterinary histology, Mosby-Year Book, Inc.

Baumel J J, King AS, Breazile J E, Evans HE, Vanden Berge JC (1993). Handbook of avian anatomy: Nomina Anatomica Avium, Publication No. 23. Publications of the Nuttal Ornithological Club, Cambridge, Massachusetts, USA.

Benkman CW and Lindholm AK (1991). The advantages and evolution of a morphological novelty. Nature 349(6309): 519-520.
Berkhoudt H (1975). The epidermal structure of the bill tip organ in ducks. Netherlands Journal of Zoology 26(4): 561-566.

Clipsham R (1997). Beak repair, rhamphorthotics. Avian medicine and surgery, WB Saunders Company, Philadelphia, PA: 773-786.

Colville T and Bassert JM (2008). Clinical Anatomy \& Physiology for Veterinary Technicians. Mosby Elsevier, St. Louis, London and Philadelphia.

Crole M and Soley J (2010). Gross Morphology of the IntraOral rhamphotheca, Oropharynx and Proximal Oesophagus of the Emu (Dromaius novaehollandiae). Anatomia Histologia and Embryologia 39(3): 207-218.

Farner DS, King JR, Parkes KC (2012). Avian Biology, Academic Press.

Gentle MJ and Breward J (1986). The bill tip organ of the chicken (Gallus gallus var. domesticus). Journal of anatomy 145: 79.

Gerlach H (1997 ). Anatiformes In Avian Medicine and Surgery. Quesenberry, K., W. B. Saunders Company, Philadelphia, London and Toronto.

Gottschaldt KM and Lausmann S (1974). The peripheral morphological basis of tactile sensibility in the beak of geese. Cell and Tissue Research. 153(4): 477-496.

Hodges RD (1974). The histology of the Fowl. Academic Press, London, New York and San Francisco.

Kent GC and Carr RK (2001). Comparative Anatomy of the Vertebrates. McGraw-Hill Higher Education. Singapore.

King AS (1975). Aves introduction and Aves respiratory system. In Sisson and Grossman's the Anatomy of the Domestic Animals. (R. Getty, Ed.) W. B. Philadelphia, Saunders Company, London andToronto., Bailliere Tindall.

Klasing KC (1999). Avian gastrointestinal anatomy and physiology. Seminars in Avian and Exotic Pet Medicine, Elsevier.

Leitner LM and Roumy M (1974). Thermosensitive units in the tongue and in the skin of the duck's bill. Pflügers Archiv European Journal of Physiology 346(2): 151155.

McLelland J (1975). Aves Digestive System: In Sission and Grossman's, The Anatomy of the 
Domestic Animals, Rev. R. Getty. . W. B. Saunders Company.Philadelphia and London.

McLelland J (1979). Digestive System. Form and Function in birds. Vol I, pp: 101131.(Ed.) AS King and J. McLelland, Academic press, London.

Moreng RE and Avens JS (1985). Poultry Science and Production. Reston Publishing Company Inc., Reston, Virginia.

Nickle R, Schummer A, Seiferle E. (1977). Anatomy of the domestic bird. Translated by SILLER, WG and PA WIGHT. Verlag, Paul Parey, Berlin: 72-75.

Nudds TD and Bowlby JN (1984). Predatorprey size relationships in North American dabbling ducks. Canadian Journal of Zoology. 62(10): 2002-2008.

Perrins C (1982). The encyclopedia of birds. Peerage books, London.
Roach R (1952). Notes on the New Zealand Kiwis (I). New Zealand Veterinary Journal 1(2): 38-39.

Stastny K (1985). Birds of Sea and fresh water, Hamlyn.

Tadjalli M, Mansouri SH, Poostpasand A (2008). Gross anatomy of the oropharyngeal cavity in the ostrich (Struthio camelus). Iranian Journal of Veterinary Research 9(4): 316-323.

Tivane C (2008). A morphological study of the oropharynx and oesophagus of the ostrich (Struthio camelus), MSc dissertation.

Zusi RL (1987). A feeding adaptation of the jaw articulation in New World jays (Corvidae). The Auk: 665-680.

Zweers G and Wouterlood F (1973). Functional anatomy of the feeding apparatus of the mallard (Anas platyrhynchos L.). Proc III Europian Anatomy Congress 88: 89. 